Issued by Sandia Laboratories,

a prime contractor to the United States Atomic Energy Commission

\title{
NOTICE
}

This report was prepared as an account of work sponsored by the United States Government. Neither the United States nor the United States Atomic Energy Commission, nor any of their employees, nor any of their contractors, subcontractors, or their employees, makes any warranty, express or implied, or assumes any legal liability or responsibility for the accuracy, completeness or usefulness of any information, apparatus, product or process disclosed, or represents that its use would not infringe privately owned rights.

\section{Printed in the United States of America}

Available from:

National Technical Information Service

U.S. Department of Commerce

5285 Port Royal Road

Springfield, Virginia 22151

Price: Printed Copy $\$ 3.00$; Microfiche $\$ 0.95$ 


\section{DISCLAIMER}

This report was prepared as an account of work sponsored by an agency of the United States Government. Neither the United States Government nor any agency Thereof, nor any of their employees, makes any warranty, express or implied, or assumes any legal liability or responsibility for the accuracy, completeness, or usefulness of any information, apparatus, product, or process disclosed, or represents that its use would not infringe privately owned rights. Reference herein to any specific commercial product, process, or service by trade name, trademark, manufacturer, or otherwise does not necessarily constitute or imply its endorsement, recommendation, or favoring by the United States Government or any agency thereof. The views and opinions of authors expressed herein do not necessarily state or reflect those of the United States Government or any agency thereof. 


\section{DISCLAIMER}

Portions of this document may be illegible in electronic image products. Images are produced from the best available original document. 


\title{
R. $-6: 8-3747 X$
}

DRAFT

DEVELOPVENT OF NEW DIEIECTRIC SYSTEMS TO PROVIDE A MINIMUM

VOLUMETRIC EFFICIENCY OF TEN JOULES PER CUBIC INCH

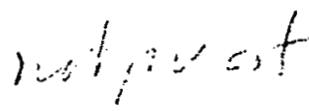

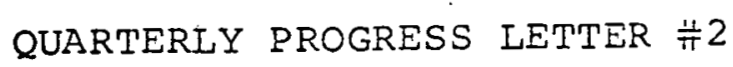 \\ Period: May 8, 1968 to August S, 1968
}

To Sandia Ccrporation

Albuquerque, New Mexico

Contract No. 57-5750

Buyer: J. L. Miller, 4312

Raquester: A. F. Hurfora, 1432

SPRÄGUE ELECTRIC COMPRNY

North Adams, Massachusetts

septemoer 9, 1968
This report was proTICE

This report was prepared as an account of work sponsored by the United States Government. Neither Cominission Utates nor the United States Atomic Energy their contractors, any of their employees, nor any of makes any warranty, express or implied, or assumes any legal liability or responsibility for the accuracy, completeness or usefulness of any information, apparatus, product or process disclosed, or represents that its use
would not infringe privately owned rights. 
TABLE OF CONTENTS

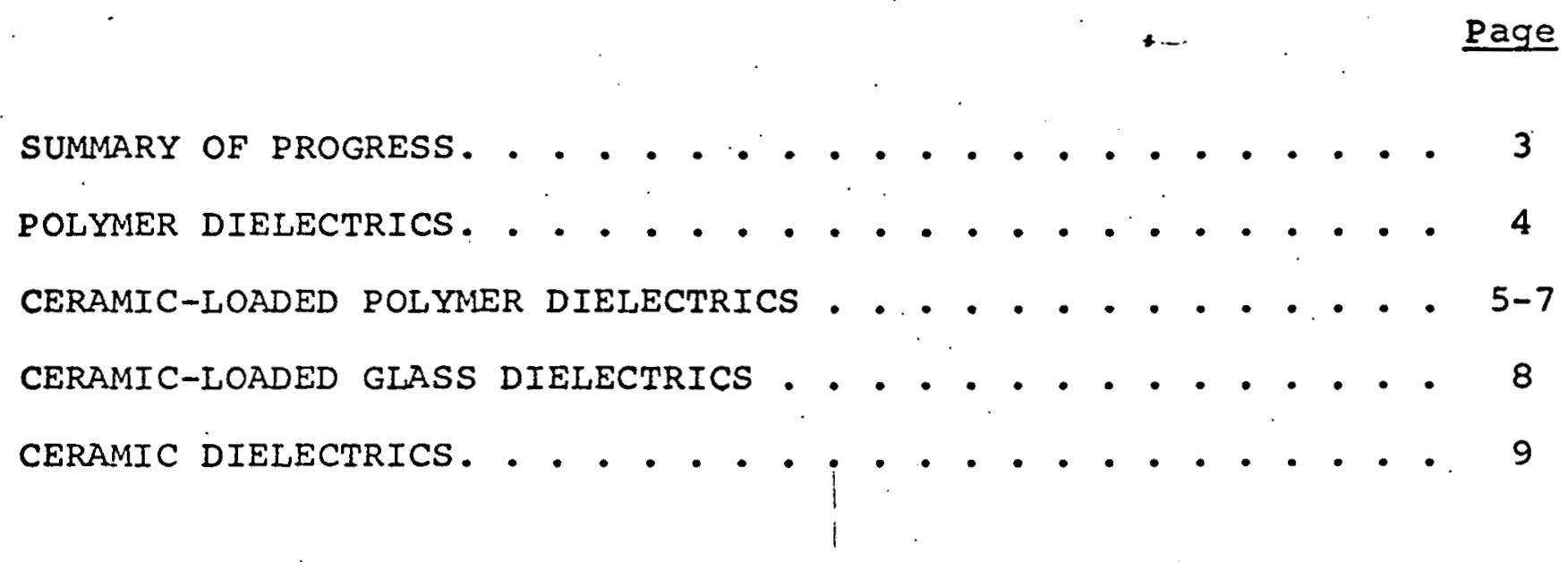




\section{SUMMARY OF PROGRESS}

The studies of polymer films loaded with barium titanate have been aimed at gathering needed information to cast loaded film on a production scale. The problems of getting fine dispersion have been fully solved and engineering studies for commercial scale casting have included variations of various lots of barium titanate powder, of solvent purification requirements, of optimum polymer concentrations for ball-milling dispersions, and of various lots of polycarbonate. Process improvements have been initiated to limit the brittle character of highly loaded films and the use of polymeric plasticizers has shown definite improvement but not enough for commercial processing at present.

The evaluation of unloaded polymer films was continued and during this quarter break-down voltages of $15 \mathrm{kV}$ per mil were obtained with a chlorinated polyvinyl chloride film. These results . compare very favorably with Mylar.

In studies of barium titanate powders dispersed in a glass matrix, we have found that we can decrease the glass content to as low as $15 \%$ (by volume) and these compositions have a dielectric constant of about 1000; dielectric strengths to date are relatively low.

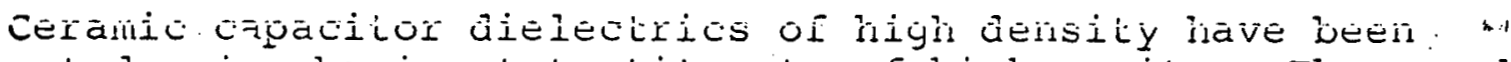
fabricated using barium tetratitanate of high purity. The resulting dielectrics had dielectric strength of as high as $1.3 \mathrm{kV}$ per mil. which is unusually high for ceramic materials. 
POLYMER DIELECTRICS

H. Kachi

I. Dielectric Strength of Heat-Treated Chlorinated polyvinylchloride

Films of Geon vinyl 101-EP ( $1 / 2$ mil thick) were cast from 12 per cent solutions in tetrahydrofuran. In the following table. sample no. 1 was heated at $55^{\circ}$ for one hour; sample no. 2 was the identical sample further heated at $65^{\circ}$ for one hour, etc. Therefore, each sample designation has received a cumulative heat treatment of all the samples above it.

$\begin{array}{ccc}\text { Sample Heating Temp. }{ }^{\circ} \mathrm{C} & \begin{array}{c}\text { Break-down Voltage, } \\ 25^{\circ} \mathrm{C}(\mathrm{KV} / \mathrm{mil})\end{array} \\ 1 & 55 & 12.0 \pm 1.3 \\ 2 & 65 & 13.7 \pm 2.7 \\ 3 & 75 & 14.0 \pm 2.9 \\ 4 & 85 & 14.2 \pm 2.0 \\ 5 & 95 & 13.8 \pm 1.6 \\ 6 & 105 & 15.1 \pm 1.4 \\ 7 & 115 & 14.2 \pm 1.7 \\ 8 & 125 & 14.4 \pm 2.3 \\ 9 & 135 & 15.4 \pm 0.9 \\ 10 & 145 & 16.8 \pm 1.7\end{array}$

Dielectrics strengths achieved by the above thermal treatment are comparable to that of heat-treated Mylar, but the Geon chlorinated PVC softens at $110^{\circ} \mathrm{C}$.

II. Heat Treatment of Mylar Film

Further experiments were run to determine the cause for the improvement of dielectric strength of $1 / 2-$ mil film. 
Density Amorphous Content

Treatment

$\left(25^{\circ} \mathrm{C}\right)$

by Density

$\mathrm{D}_{898^{\prime}} \mathrm{D}_{79.5} \mathrm{~V}_{\mathrm{BD}}, \mathrm{KV} / 0.5 \mathrm{mil}$

none

1.396

$40.4 \%$

0.714

$5.7 \pm 0.4$

$250^{\circ} \mathrm{C}$ for

1 minute

1.390

$44.4 \%$

1.23

$8.1 \pm 0.3$

The ratio of infrared band intensities $\mathrm{D}_{898} / \mathrm{D}_{795}$ is proportional to the amorphous content. According to the infrared measurements, the heated film should contain 1.72 times as much amorphous material as the untreated, but according to density measurements only 1.10 times as much. We suspect the density measurement. is in error because of the presence of voids in the untreated Mylar which anneal out in the heat treatment. 
Tabj.e 1

Summary of Film Electrical Properties

Volume per cent $\mathrm{BaTiO}_{3}$

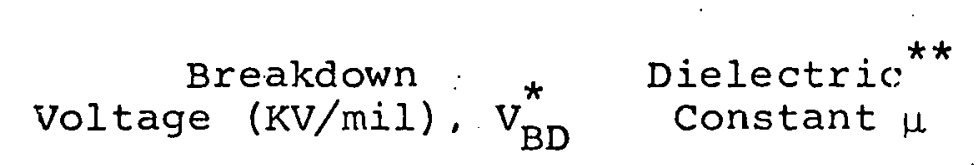

3.2

7.3

26.8

35.2

3.1

Insulation Resistance (megohm-ufarad)

$-44^{-}$

110
$16.5 \pm 2.0$

$6.2 \pm 1.2$

$$
5.0 \pm 1.0
$$$$
4.7 \pm 0.6
$$

${ }^{*}$$$
\text { S1 }
$$
S Sputtered 3/4" copper electrodes

\section{Energy Storage Factors} at Breakdown

Volumetric Gravimetric

$\begin{array}{ccc}\left(\mathrm{V}_{\mathrm{BD}}\right)^{2} \times \in & \frac{\left(\mathrm{V}_{\mathrm{BD}}\right)^{2} \times \frac{\epsilon}{\mathrm{DENSITY}}}{122} & 75 \\ 292 & 135 \\ 670 & 250 \\ 780 & & \\ 840 & & \\ 8 & & \end{array}$

"Short-time method in silicone oil ("point" contacts) at room temperature.
Excellent agreement was found between this method and one'employing a 3-inch square copper plate and a 1/4-inch diameter copper rod as electrodes.




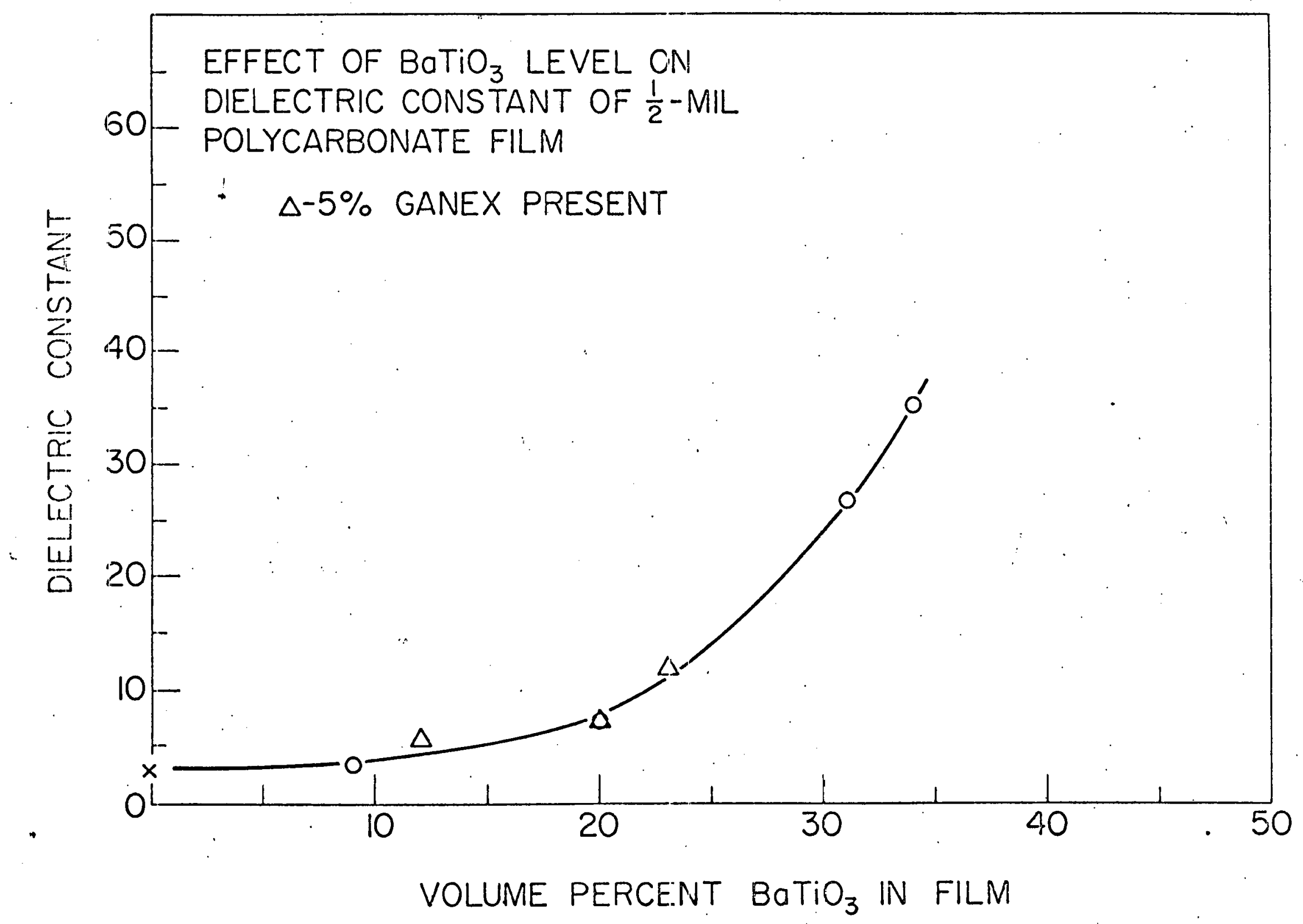


CERAMIC-IOADED POLYMER DIELECTRICS

D. Kelley and H. Kachi

The studies of polymer films loaded with barium titanate have been aimed at gathering needed information to cast loaded film on a production scale. The problems of getting fine dispersion have been fully solved and engineering studies for commercial scale casting have included variations of various lots of barium titanate poivder, of solvent purification requirements, of optimum polymer concentrations for ball-milling dispersions, and of various lots of polycarbonate.

Comparisons of loaded films were made with $\mathrm{BaTiO}_{3}$ powders which had been calcined by a rotary drum technique versus powders calcined by a fluid bed technique. No significant differences were observed in dielectric breakdown strengths of comparably loaded films.

The use of unpurified dioxane is suitable for milling $\mathrm{BaTiO}_{3}$ powaer. Fairly good dielectric strength is found in films made using this type dispersion plus polycarbonate solution made using purified dioxane. However, concentrated polycarbonate solutions (15\%) made using unpurified dioxane are cloudy and gel much more rapidly than when dried and distilled solvent is used.

The powder can also be milled in concentrated (15\%) polymer solution to give predominantly sub-micron particle size. However, for a given milling time a higher concentration of large aggregates is present than when a dilute suspension is milled.

Our current laboratory procedure in preparing loaded films. is as follows:

Barium titanate powder was milled in dilute polycarbonatedioxane solution to reduce aggregate size. After settling the supernatant was decanted to give a dispersion containing $40-45$ weight per cent $\mathrm{BaTiO}_{3}$. Casting solutions were prepared by mixing various ratios of the above dispersion and a 15 weight per cent solution of polycarbonate (Merlon M-60) in dioxane. The mixtures were cast on a glass plate using a 0.003 inch applicator; the films were alloved to dry to about $1 / 2 \mathrm{mil}$ thickness at room temperature and then were baked 24 hours at $110^{\circ} \mathrm{C}$.

Typical properties of polycarbonate films loaded with various amounts of barium titanate are summarized in Table 1 and Figure 1 .

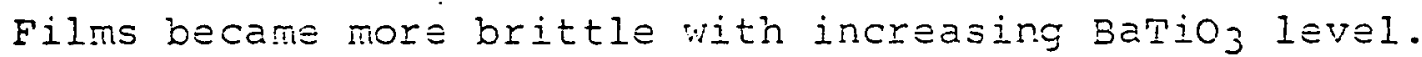
BredK-Gow roitace vaiues given in the taci e were obiaineci

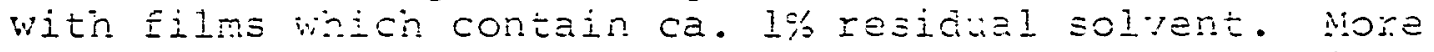

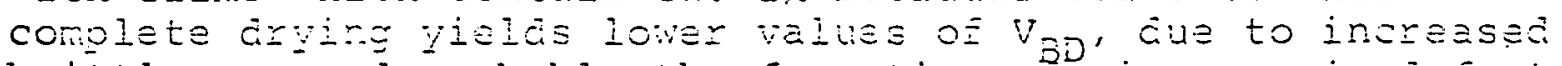
brittleness and probably the formation o: microscopic dietects 
during handling. Moisture content is also an important factor. After the standard 24 hour bake, a film stored in a desiccator with Drierite had a $V_{B D}$ value 20 per cent higher than one stored under room conditions.

Films containing 20 volume per cent BaTio 3 were made less brittle by incorporating $5 \%$ (based on polycarbonate) of either Ganéx V-804 or V-904, polyvinylpyrrolidone-based dispersants. However, a $20 \%$ reduction in break-down voltage occurs. In addition, $20 \%$ Ganex level failed to render flexible heavily filled films (ca. $40 \% \mathrm{BT}$ ). (The milky appearance of films containing no $\mathrm{BaTiO}_{3}$ indicates the Ganex polymers are not completely compatible with polycarbonate.) A similar decrease of $20 \%$ in $\mathrm{V}_{\mathrm{BD}}$ accompanied the incorporation of $5 \%$ Hycar CTBN (Iiquid rubber) in films containing 27 and 35 volume per cent BaTiO 3 . The films were not noticeably less brittle due to the Hycar.

The voltage coefficient of capacitance was measured for a 1/2-mil $\mathrm{BaTiO}_{3}$ filled polycarbonate film having a break-down voltage of $6.1 \pm 0.6 \mathrm{KV} / \mathrm{mil}$. The dielectric constant at zero applied D.C. bias was $\epsilon=8.3$. The observed per cent decrease in capacitance was $1.9 \%$ and $5.2 \%$ for 500 and 1000 volts $/ \mathrm{mil}$ bias respectively.

Two other polymers were examined as possible binders for baijo 3 . The Geon PVC-type matorial shows good dielectris strength but softens near $110^{\circ} \mathrm{C}$. The loaded Geon was quite flexible despite heavy loading.

$\begin{array}{cccc}\begin{array}{c}\text { Polymer } \\ \text { Vol.\% BaTiO }\end{array} & \begin{array}{c}\text { Breakdown } \\ \text { Voltage }(\mathrm{KV} / \mathrm{mil})\end{array} & \begin{array}{c}\text { Dielectric } \\ \text { Constant }\end{array} \\ \text { Geon 101-EP } & 0 & 12.0 \pm 2.3 \\ \text { Geon 101-EP } & (36) & 4.0 \pm 0.3 \\ \text { Vitel PE-200 } & (28) & 2.7 \pm 0.6\end{array}$




\section{CERAMIC-LOADED GLASS DIELECTRICS}

\section{Burn}

Investigation of the influence of glass composition on the dielectric properties of barium titanate-in-glass composites has continued. For the most part this has consisted of examining the effect of additions of CdO, Zno or $\mathrm{BaTiO}_{3}$ to a lead-bismuth-borate glass that had given promising results earlier.

It has been found that the formation of extraneous phases during sintering is a major cause of reduced permittivity of composites of this type. Silicate or borate phases readily form if the softening temperature of the glass is high (above about $\left.900^{\circ} \mathrm{C}\right)$, and new titanate phases are usually produced when fluxing agents ( $\mathrm{PbO}, \mathrm{Bi}_{2} \mathrm{O}_{3}$ ) are added to the glass. Glasses containing BaO, some with additions of $\mathrm{BaF}_{2}$, are presently being tried in an attempt to suppress the formation of secondary phases. With 45 vol.\% glass, the dielectric constant of the composites is commonly 250-300 when the lead-bismuth-borate glasses are used, with or without additions of $10 \mathrm{wt} \% \mathrm{CdO}$, Zno or $\mathrm{BaTiO}_{3}$. Higher dielectric constants, up to about 400 , can be obtained with composites in which (semiconducting) $C d o$ is precipitated from the glass during firing: but the diel ectric strength is reduced in this case.

Densificalion has been found to occur with smaller amounts of glass than was earlier thought possible. This is because the barium titanate is usually soluble to some extent in the glasses used, and sintering can take place by the solution and precipitation process. Composites containing only 15 vol\% glass have been prepared with a dielectric constant above 1000 but the dielectric strengths are relatively poor. The range between 15 vol\% and 45 vol\% has yet to be explored.

The dielectric strengths of composites containing 45 vol.\% glass generally range from approximately 350 to 1000 volts per mil. Addition of cdo to lead-bismuth-borate glass, whilst not influencing the dielectric constant of the composites appreciably, appears to improve the dielectric strength. The measured strengths, however, are very sensitive to fabrication faults (porosity, non-uniform thickness, etc.) and this often masks the intrinsic strength of the material. Efforts are therefore being made to sinter the composite to as near theoretical density as possible so as to realize the optimum strengths of the materials.

It is intended to begin discharge tests on some of the materials prepared so far. Thick film units are being made and wiil be tested as soon as the assembling of the necessary equipment is completed. 


\section{CERAMIC DIELECTRICS}

\section{R. P. Auty}

One of the limitations of normal ceramic capacitors is the low dielectric strength in comparison to other dielectric materials, and, therefore, these have not been used for energy storage. Improvement is worth investigation if the breakdown field is limited by porosity or charge carriers accumulated by diffusion on the outside of the grains.

Our program is to investigate the electrical properties of high density, non-ferroelectric polycrystalline ceramic bodies. Barium tetratitanate was chosen as a low dielectric constant material which is made in high purity and sinters easily to high density. The nonferroelectric material was chosen to avoid fielddependence of capacity and the mechanical shock of rapid capacitor discharge.

Table 2 shows the results of breakdown testing of barium tetratitanate sintered in air with a density $98 \pm 0.5 \%$ of $x-r a y$ density. Electrodes vere applied immediately after firing. Although the resuits were promising, the hypothesis was madeiand conrirmed in Table 2) that the control of the oxygen partial pressure during firing would also affect the electrical characteristics. Consequently, annealing studies were carried out in an attempt to approach. equilibrium conaitions. Not only were the high voltage test results improved but large improvements were noted in temperature coefficient of capacitance and in the ac losses at $130^{\circ} \mathrm{C}$ (Table 3 ). It should be noted that the ac losses for all units were too small at room temperature to be measured on our bridge. 


\section{Table 2}

Barium Tetratitanate

Breakdown Testing sputtered Electrodes

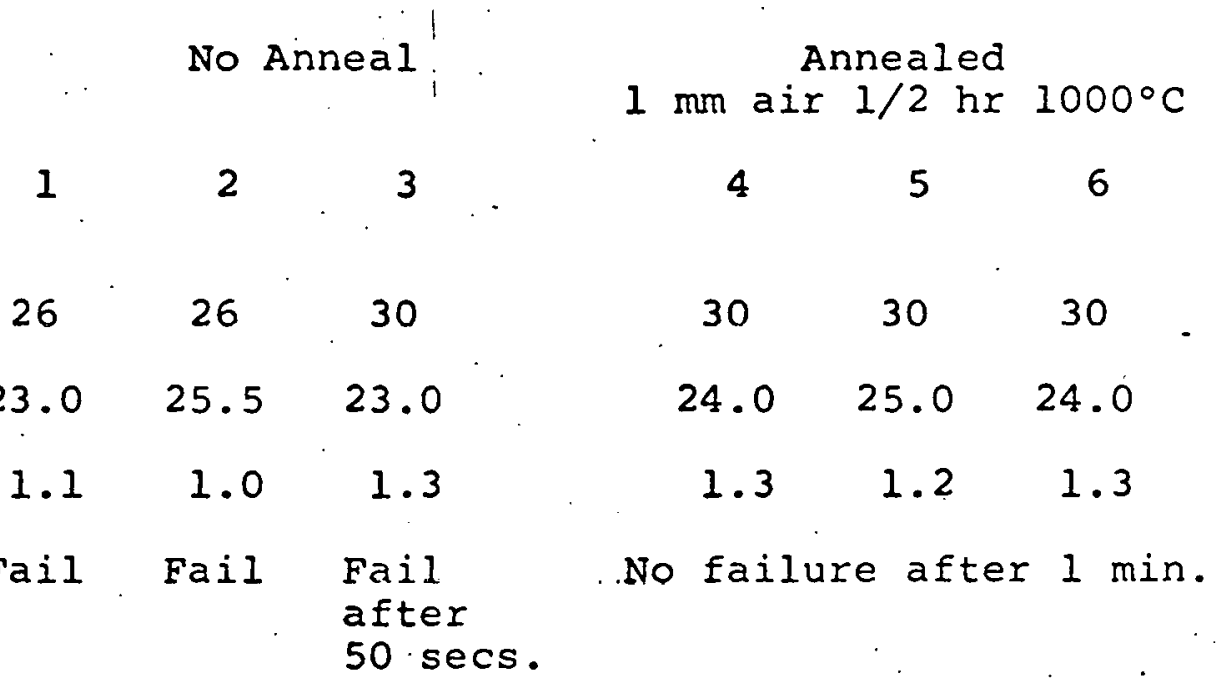




\section{Table 3}

Barium Tetratitanate
- Anneal

Conditions $1225^{\circ} \mathrm{C}$

760

air

1

Time hr

$25^{\circ} \mathrm{C}, I \mathrm{KHz}$

$130^{\circ} \mathrm{C}, \mathrm{K} / \mathrm{KHz}$

39.8

39.9

38.9

$39.9 \quad 39.9$

47.

46.6

43.9

$42.5 \quad 46.6$

.45 .7

.1312

.3874

.2107

2482

.1695 .1730

Temp coeff ppm $\left(25^{\circ}-130^{\circ} \mathrm{C}\right.$

$+1890$

$+1599$

$+1224$

$+620$ $98.4 \quad 98.7 \quad 98.4 \quad .98 .4$

1000

.5

$\mathrm{O}_{2}$

$1 / 2$

45.2

\% X-ray Density

98.5
$+1599$

$+105$

94.9
$1200 \quad 1180$

5.5

air air

11

$38.6 \quad 34.1$

$33.4 \quad .39 .8$

$.1526 \quad .0284$

$-1283+1592$

$98.6 \quad 98.5$ 